\title{
Study of the Variation of Antioxidant Contents According to the Variety and the Position of the Fruit (Mango) Picking on the Plant from Five Varieties of Mango in Senegal
}

\author{
Ibrahima Ba*, Mouhamadou Fofana, EI Hadji Gorgui Diouf, Moussoukhoye Diop \\ Chemistry Department, Faculty of Science and Technology, Cheikh Anta Diop University, Dakar, Senegal \\ Email address: \\ Baibrahima705@gmail.com (I. Ba), fofpc@yahoo.fr (M. Fofana), goorgui82@yahoo.fr (El H. G. Diouf), moussou_diop@yahoo.fr (M. Diop) \\ ${ }^{*}$ Corresponding author
}

To cite this article:

Ibrahima Ba, Mouhamadou Fofana, El Hadji Gorgui Diouf, Moussoukhoye Diop. Study of the Variation of Antioxidant Contents According to the Variety and the Position of the Fruit (Mango) Picking on the Plant from Five Varieties of Mango in Senegal. Advances in Biochemistry. Vol. 9, No. 2, 2021, pp. 29-38. doi: 10.11648/j.ab.20210902.13

Received: May 10, 2021; Accepted: May 31, 2021; Published: June 21, 2021

\begin{abstract}
This study is carried out on five varieties of mangoes exploited in Senegal (village of Kaguitt), two of which are intended for export and the three for local consumption on the one hand and national marketing on the other. The objectives of this study were to identify the varieties richest in antioxidants and to understand whether the position of the fruit (mango) harvest has an influence on its antioxidant levels. To carry out this study, we used the method developed by (Georgé et al., 2005) for the determination of polyphenols and the method of Adaramola et al. (2016) for evaluation of antioxidant activity. The results on the variation in antioxidant activity, total polyphenols and flavonoids show an influence of variety and position. However, the variation of these contents is difficult to observe at first sight. From statistical analyses, we can see that the position and variety effects are dependent, i.e. that these levels vary according to the two parameters. Compared to the antioxidant activity content, the Sl (top position) and Knt (middle position) varieties are respectively the richest 50\%inhibition and 40\%inhibition. For the polyphenolic composition this variation according to position has not much effect, however the varieties Dr and Bk remain the richest $0.6 \mathrm{mgeqAc} / 100 \mathrm{~g}$ and $0.5 \mathrm{mgeqAc} / 100 \mathrm{~g}$. The results on the flavonoid content show that the Intermediate position of the Dr variety (11 mgeqAc/100g) contains by far the most flavonoids than the other positions of the other varieties. However, its flavonoid content is not statistically significant compared to the Intermediate position of the variety SL. This study reveals that the SL, Dr and Knt varieties can be the basis of an antioxidant-rich diet in Senegal. They can also be used in several food areas.
\end{abstract}

Keywords: Mangifera Indica L., Contents, Composition, Position, Antioxidants, Consumption, Local, and Export

\section{Introduction}

Today several food sources are used to satisfy the body's needs [1]. Among foods, fruits and vegetables play an important role due to their nutritional composition [2]. However, the mango remains one of the most accessible and most exploited fruits in Senegal. Indeed, mango, a remarkable fruit, is known for its richness in antioxidants, mainly provitamin A and vitamin C with about $27 \mathrm{mg} / 100 \mathrm{~g}$ fresh matter [3]. Half a mango is enough to cover the total daily requirement of provitamin $\mathrm{A}$ and more than $66 \%$ of the total recommended requirement for vitamin C. Moreover, with an energy intake of 56 kilocalories per $100 \mathrm{~g}$ of fruit, mango is one of the medium calorie fruits [4].
However, the nutritional specificity of a fruit is linked to its composition, which in turn depends on the species, variety, degree of ripeness, growing and storage conditions [5]. In Senegal, the varieties appreciated and exported are Kent and Keitt, although others are interesting for export (Tommy Atkins, Zill, Palmer) and several local mango varieties: diorou, sierra-leone, papaya, boukodiékhal, balanta, passy, thias... Kent remains the most sought-after variety for its colour, taste and low fibre content, which is leading more and more producers to invest in plantations of this variety and/or to renew existing orchards using the grafting technique [6]. The objective of this work is: the study of the variation in total polyphenol composition and antioxidant activity depending on the variety and the position where the fruit was picked on 
the plant. This study will first of all make it possible to identify the variety(s) of mango that is (are) the richest in antioxidant activity and/or polyphenols and/or flavonoids. In a second step to see if the variation of this composition is significant compared to the position where the fruit was harvested on the plant. To carry out this study, five varieties of mango were characterized, two of which are intended for export (Kent and Keitt) and three for local consumption and national marketing.

\section{Materials and Methods}

\subsection{Origin of Samples}

The mango samples used in this work come from two areas of Senegal: Kaguitt village in the Ziguinchor region and Keur Mbir Ndao in the Thies region. In the southern zone, four varieties of mango were collected, two of which are for export and two varieties specific to the locality for national marketing, which are highly prized by consumers. In the Niayes zone, one variety was collected for national marketing.

\subsection{Sampling Techniques}

Each variety is harvested from three mango trees in three levels per mango tree (top level, intermediate level and bottom level). The varieties for export taken from the southern zone are: Kent and Keitt, and the local varieties Diourou and Sierra Leone are taken from the southern zone and the Boukodiekhal variety from the Niayes zone.

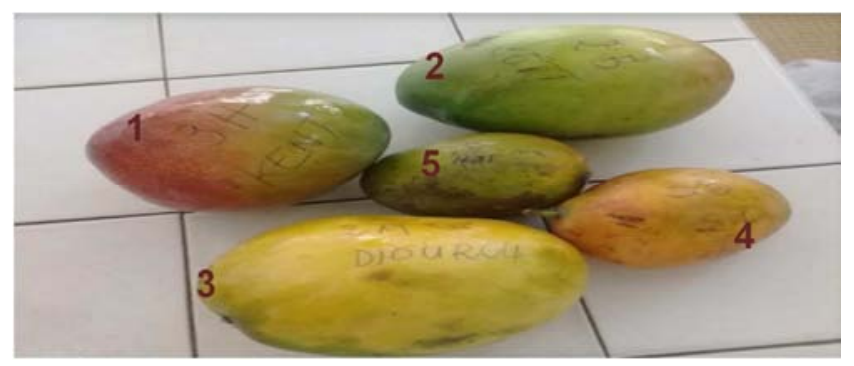

Figure 1. Mangifera indica L. var. 1 Kent; 2. Keitt; 3. Diourou; 4. Sierra Leone and 5. Boukodiekhal.

\section{Determination of total polyphenols:}

For polyphenols, the Folin-Ciocalteu method is used, which consists of oxidizing the oxidizable groups of phenols in a basic medium. The blue-coloured reduction products have an intensity of absorption proportional to the quantity of polyphenols present. Absorbances are read at $760 \mathrm{~nm}$. In fact, it is a calibration method using a gallic acid solution taken as the reference polyphenol. From this standard solution, daughter solutions are prepared with concentrations ranging from 0.01 to $0.1 \mathrm{~g} / \mathrm{l}$. The $\mathrm{OD}=\mathrm{f}(\mathrm{C})$ curve, i.e. the linear (affine) response calibration curve, can thus be plotted. Thus, the results calculated from the mean of three trials are expressed in $\mathrm{g}$ of gallic acid equivalents per $100 \mathrm{~g}$ of extract.

For this purpose, $50 \mu$ l extract is determined using the Folin-Ciocalteu reagent according to the method developed by (Georgé et al., 2005).

The concentration of total polyphenols is given by the relation:

$$
C_{P}=\frac{(A-b)}{a} * F d * \frac{v}{1000} * \frac{100}{m}
$$

$\mathrm{Cp}$ : Total polyphenol content expressed in gallic acid equivalent/100 g;

A: Actual absorbance of the sample;

a: Directing coefficient of the calibration line $=3.12$;

b: Originally ordered by the calibration line $=0.0696$;

Fd: Dilution factor;

$\mathrm{v}$ : Extraction volume $(\mathrm{mL})$;

$\mathrm{m}$ : Test sample $(\mathrm{g})$.

Flavonoids dosage:

The flavonoid content of the extracts is determined using the colorimetric method described by (6). The results are expressed in $\mathrm{g}$ catechin equivalent per $100 \mathrm{~g}$ of product.

$$
C=\frac{A * P m}{\varepsilon} * f d * \frac{v}{1000} * \frac{100}{m}
$$

$\mathrm{C}$ : Total flavonoid content expressed in $\mathrm{g}$ catechin equivalent/100 g;

A: Absorbance of the sample;

Pm: molar mass of catechin $=290.26 \mathrm{~g} / \mathrm{mol}$;

$\varepsilon$ : Coefficient of molar extinction $=10,332 \mathrm{~L} / \mathrm{mol} . \mathrm{cm}$;

Fd: Dilution factor;

$\mathrm{v}$ : Extraction volume $(\mathrm{mL})$;

$\mathrm{m}$ : Test sample $(\mathrm{g})$.

The antioxidant activity was evaluated with 2, 2-diphenyl-1-pycrilhydrazyle (DPPH) according to the method of (Adaramola et al,. 2016).). In addition, some adjustments have been made to this protocol. The method is based on the ability of an extract to give a singlet electron to the dark purple-colored DPPH free radical to stabilize it in yellow-green DPPH. This activity is compared to that of a control antioxidant (quercetin). Thus, $2 \mathrm{~mL}$ of DPPH $(0.1 \mathrm{mM}$ in alcohol) was introduced into a test tube containing $0.5 \mathrm{~mL}$ of sample. The mixture was stirred for five (5) minutes, then incubated in the dark and at room temperature for 30 minutes. After this incubation period, the absorbance was read at 517 $\mathrm{nm}$ against a blank $(0.5 \mathrm{~mL}$ of sample and $2 \mathrm{~mL}$ of methanol) using a UV spectrophotometer (SPECORD 200 PLUS). The anti-radical activity is expressed as a percentage of DPPH reduced according to the equation

$$
A A R(\%)=\frac{\text { Absorbance }_{\text {contrôle }}-\text { Absorbance échantillon }_{\text {éch }}}{\text { Absorbance }_{\text {contrôle }}}
$$

Also, the concentration of baobab oil reducing $50 \%$ of DPPH (IC50) is determined graphically on the curve of anti-free radical activity (AAR) as a function of the oil concentration [7].

\section{Results and Discussions}

\subsection{Study Variables and Varieties Studied}

Figure is as follows: Place figures and tables at the top and bottom of columns. Avoid placing them in the middle of 
columns. Large figures and tables may span across both columns.

Study variables:

a. Polyphenols (mgéqAc/100g)

b. Flavonoids (mgéqAc/100g)

c. Antioxidant activity (\% inhibition)

d. Varieties studied: Kent (Knt), Diourrou (Dr), Keitt (Kt)

Boukodiékhal (BK) and Sierra-léon (SL).
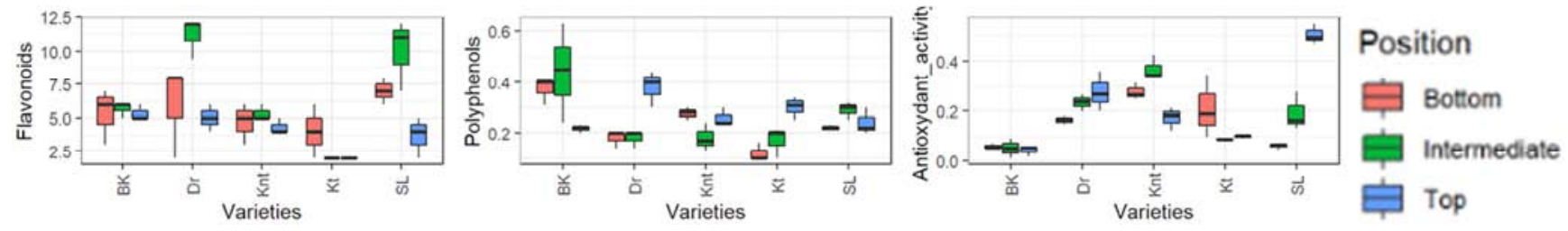

Figure 2. Description according to variety and position.

Mango, like guava and lychee, differs greatly from other tropical fruits by its high content of polyphenols (or phenolic compounds) [3]. Phenolic compounds are found in plant foods. Their antioxidant capacity would protect the cells of the body from damage caused by free radicals. They would decrease the risk of developing several diseases [8]. Their abundance and composition differ according to the varieties $[9,10]$. In this figure 1, the analysis shows differences in the composition between the varieties and according to the positions. It can be assumed that the grades studied vary according to the position and the variety. To verify this hypothesis as to whether there is a variation in the biochemical composition according to the variety and the position, it would be important to analyze each parameter.

\subsection{Study of the Antioxidant Activity According to the Variety and the Position}

Table is as follows

First, we want to explain the antioxidant activity according to the variety and the Position where the mango was picked. The explanatory variables are qualitative. We will therefore do a two-factor analysis of variance. We start by checking this in the sense of looking at the existence of a link.
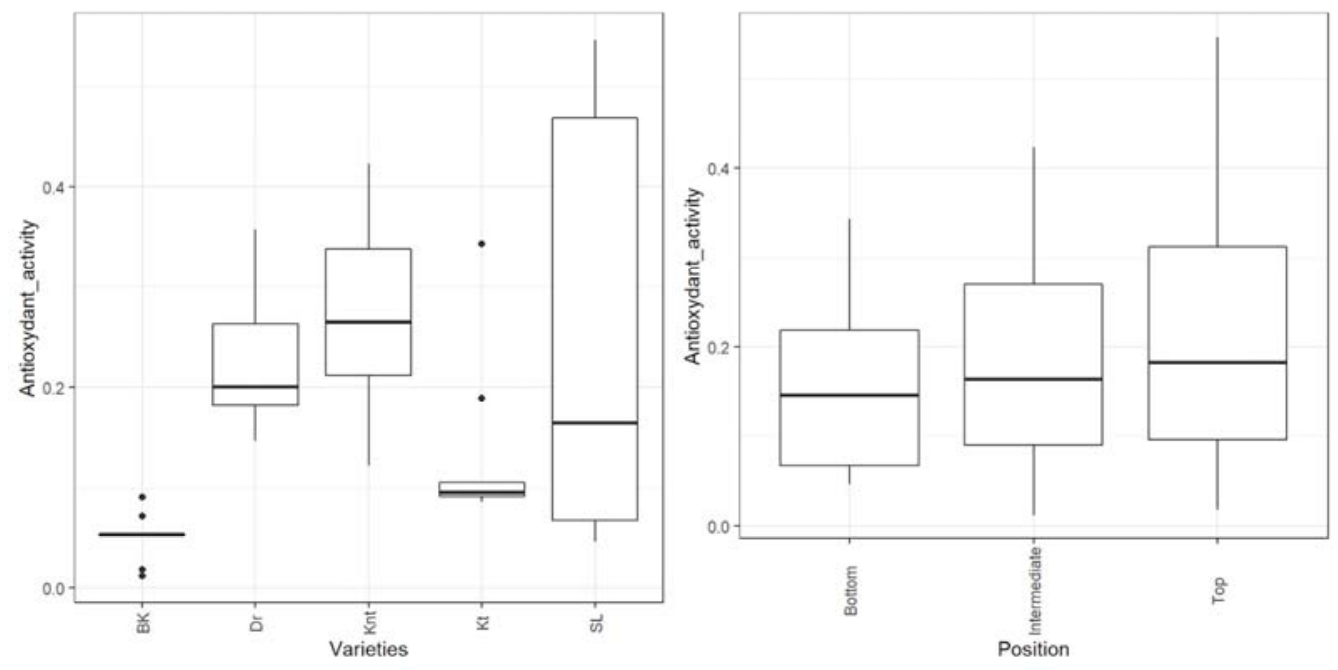

Figure 3. Two-factor analysis of variance.

From Figure 2, we see that the Variety factor has a probable influence on the Antioxidant activity variable. The influence of the Position factor is less marked. To confirm the influence of the variety on the variation in antioxidant activity, we carried out the Kruskal Wallis $\mathrm{X}^{\wedge} 2$ test $(\mathrm{p}=0.0001)$ in the following table. Mathematical formula of the Kruskal wallis test:

$$
H=(N-1) \cdot \frac{\sum_{k=1}^{k} n_{k} \cdot(\overline{R \mid Y=k}-\bar{R})^{2}}{\sum_{i=1}^{N}\left(R_{i}-\bar{R}\right)^{2}}
$$

Note that if there are tied ties on the total sample, a correction must be applied. And the value of: $\mathrm{Z}$ is

$$
Z_{J}=\frac{\overline{R_{j}}-\bar{R}}{\sqrt{\frac{(N+1)\left(\frac{N}{n_{j}}-1\right)}{12}}}
$$

Where $\overline{R_{j}}=$ average rank of group $\mathrm{j}$, $\bar{R}=$ average rank of all observations, $\mathrm{N}=$ Number of observations and 


\begin{tabular}{|c|c|c|c|c|c|}
\hline & statistic & p.value & parameter $₹$ & method $₹$ & Test \\
\hline 1 & 23.0391988932077 & 0.000124363220747736 & 4 & $\begin{array}{l}\text { Kruskal- } \\
\text { Wallis } \\
\text { rank sum } \\
\text { test }\end{array}$ & $\begin{array}{l}\text { Variation de } \\
\text { *l'activité } \\
\text { antioxidant" } \\
\sim \text { Variétés }\end{array}$ \\
\hline 2 & 1.14461646573118 & 0.564221579679631 & 2 & $\begin{array}{l}\text { Kruskal- } \\
\text { Wallis } \\
\text { rank sum } \\
\text { test }\end{array}$ & $\begin{array}{l}\text { Variation de } \\
\text { "l'activité } \\
\text { antioxidant" } \\
\sim \text { Position }\end{array}$ \\
\hline
\end{tabular}

Figure 4. Kruskal Wallis test.

According to the results of the Kruskal Wallis $\mathrm{X}^{\wedge} 2$ test $(\mathrm{p}=0.0001)$, there is at least one variety whose antioxidant activity is significantly different from other varieties and that the position effect has not a lot of influence ( $\mathrm{p}$. value $=0.5>0.0001)$.

To clearly see this difference, we carried out the Wilcoxon test in Table 1 . This test allows the varieties to be compared with each other.

Table 1. Wilcoxon test.

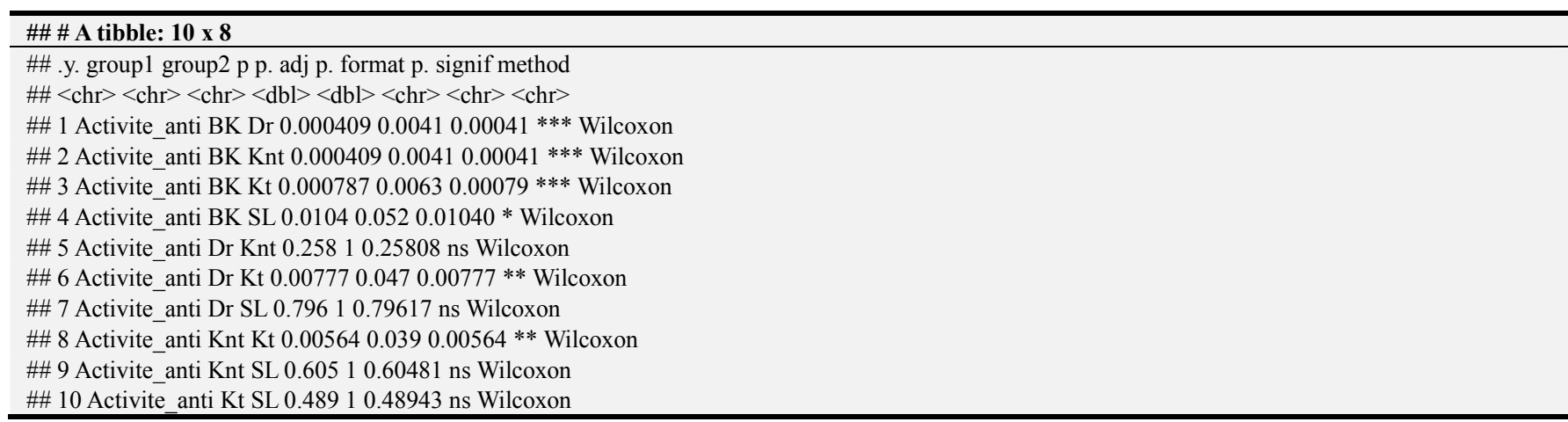

According to the table, there is a significant difference in the antioxidant activity between the fixed variety Bk and the varieties (Dr, Knt and $\mathrm{Kt}$ ) on the one hand and on the other hand, there is no significant difference on the content of antioxidant activity between the varieties Dr compared to the varieties Knt and SL. There is a slight difference between the variety Bk and Sl. However, it is not known which is or which variety (s) has (s) more antioxidant activity. To understand this, we carried out a comparison of the average antioxidant activity within each variety and its positions.

Position $\notin$ Bottom $\notin$ Intermediato $\Leftrightarrow$ Top

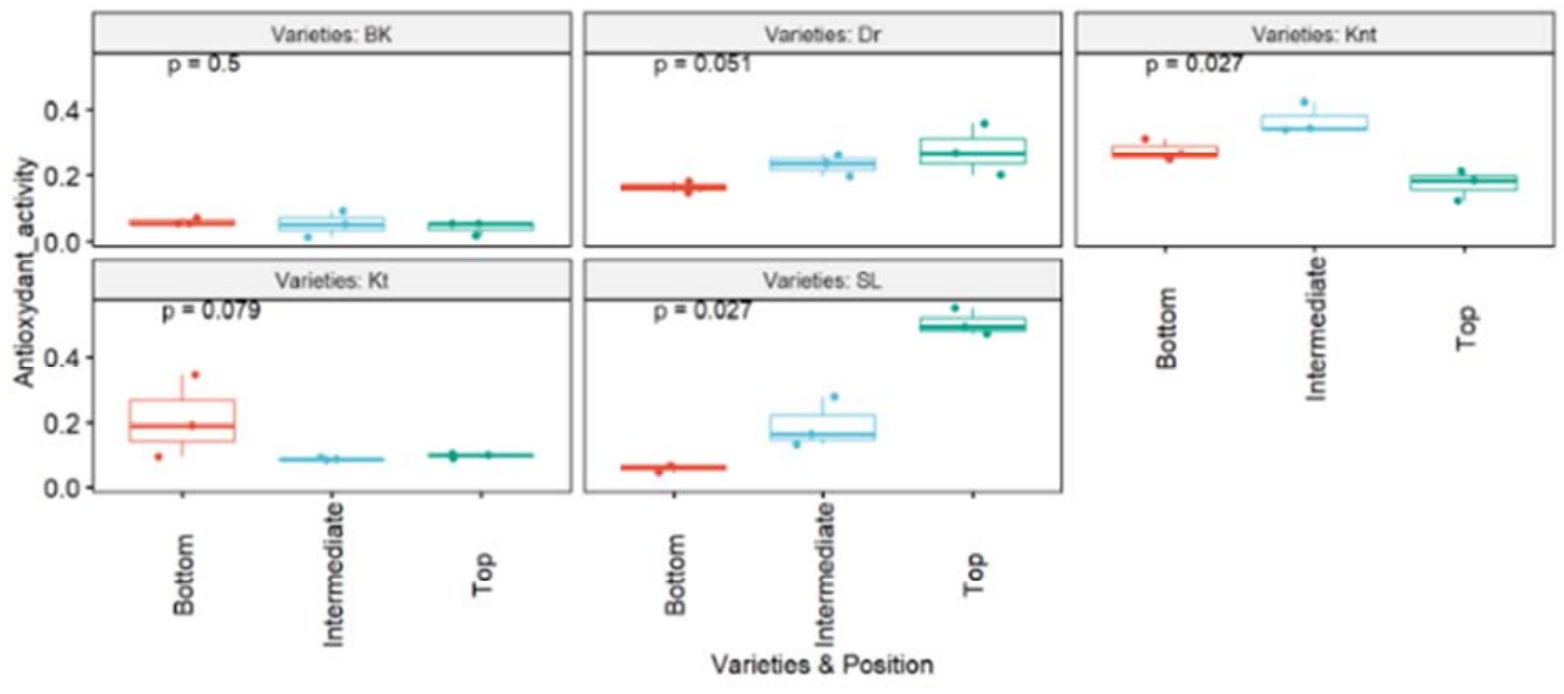

Figure 5. Variation in antioxidant activity by variety. 
From Figure 3, it is clearly seen that the varieties SL and Knt have significant contents compared to the other varieties. However, it appears from this figure that there is a variation in antioxidant activity depending on the positions, so the two factors (position and variety) are not independent. To prove this hypothesis, we visualized the effects of the couple (Variety, Position) on the average of the variable Antioxidant Activity is as follows in the figure below:
Varieties

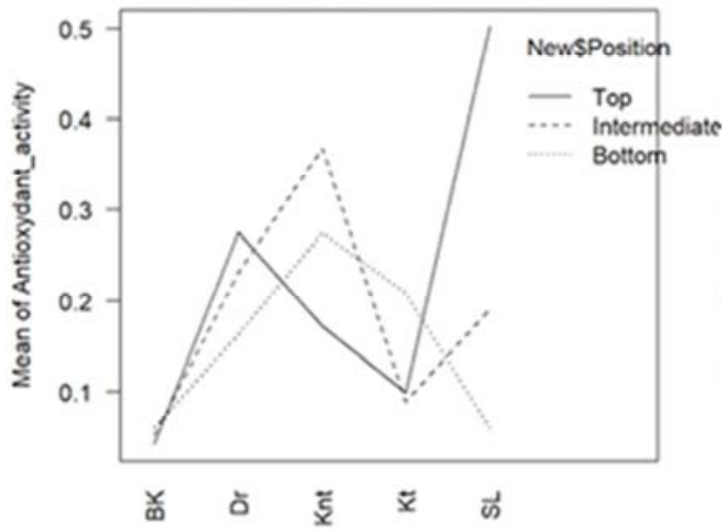

Position

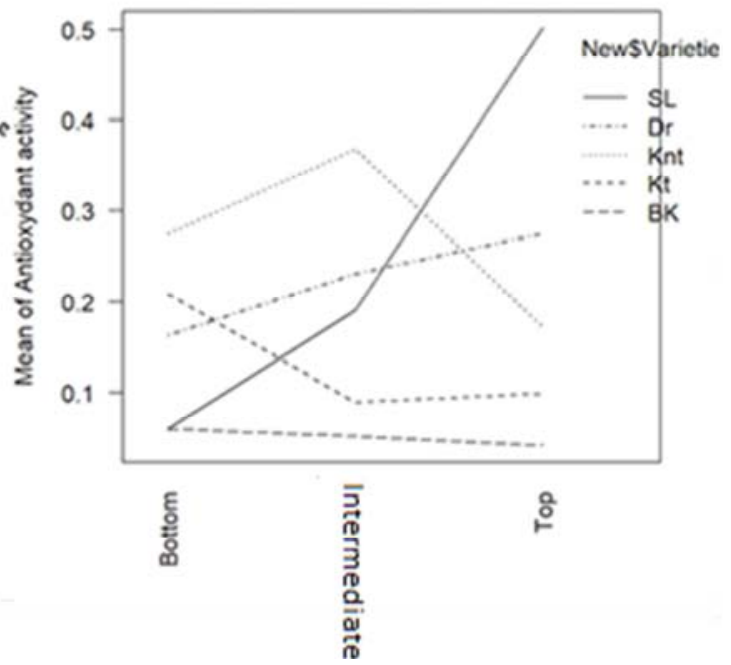

Figure 6. Visualization of couple position and variety according to the variation in antioxidant activity.

The lines are not parallel in this figure 5 , so it is assumed that there is an influence of either the position and the variety on the antioxidant content. To verify this influence, we envisage a model and an analysis of variance with interactions of factors (position and couple). The results of this model and the analysis are presented in the following figure:

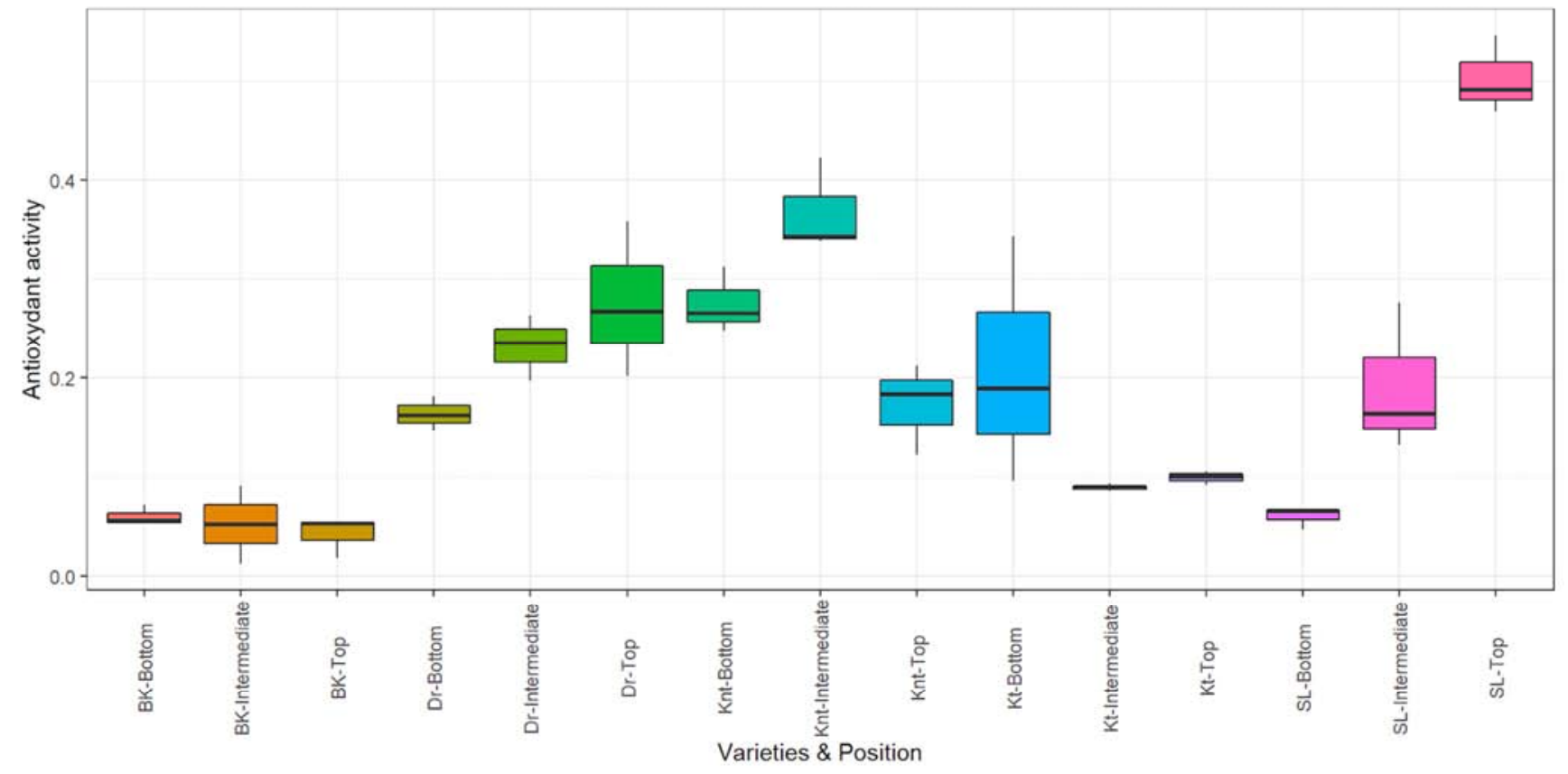

Figure 7. Model and analysis of variance.

According to figure 7, the average shows that the levels of antioydiant activity according to the positions of the varieties SL and Knt are different and that the fruits (mangoes) harvested at the top position of the variety Sl for Serra Leone seem to present more antioxidant activity. We will now use a model to confirm or refute this assumption. To do this we will set the Superior Status of the SL variety as references in order to model this hypothesis using a GLM (Generalized Linear Model) with a Negative Binomial distribution which is generally best suited for decimal data. It should be known above all that the upper position of the variety $\mathrm{Sl}$ is fixed as a reference $(0)$. The results of the model are reported in the 
following table:

Table 2. Generalized linear model.

\begin{tabular}{|c|c|c|c|c|}
\hline & Estimate & Std. Error & $\mathrm{z}$ value & $\operatorname{Pr}(>|\mathbf{z}|)$ \\
\hline (Intercept) & -0.6891552 & 0.8148694 & -0.8457247 & 0.3977063 \\
\hline Var_PositBK-Bottom & -2.1242556 & 2.4939064 & -0.8517784 & 0.3943371 \\
\hline Var_PositBK-Intermediate & -2.2737873 & 2.6675132 & -0.8523997 & 0.3939923 \\
\hline Var_PositBK-Top & -2.4888987 & 2.9434696 & -0.8455663 & 0.3977947 \\
\hline Var_PositDr-Bottom & -1.1248499 & 1.6459050 & -0.6834234 & 0.4943394 \\
\hline Var-PositDr-Intermediate & -0.7747404 & 1.4508397 & -0.5339945 & 0.5933453 \\
\hline Var-PositDr-Top & -0.6006176 & 1.3691849 & -0.4386680 & 0.6609021 \\
\hline Var_PositKnt-Bottom & -0.6030419 & 1.3702576 & -0.4400938 & 0.6598692 \\
\hline Var_PositKnt-Intermediate & -0.3105172 & 1.2529208 & -0.2478346 & 0.8042624 \\
\hline Var_PositKnt-Top & -1.0691695 & 1.6119087 & -0.6632941 & 0.5071422 \\
\hline Var_PositKt-Bottom & -0.8748315 & 1.5022063 & -0.5823644 & 0.5603213 \\
\hline Var_PositKt-Intermediate & -1.7280928 & 2.0981733 & -0.8236178 & 0.4101568 \\
\hline Var_PositKt-Top & -1.6251652 & 2.0091528 & -0.8088808 & 0.4185837 \\
\hline Var_PositSL-Bottom & -2.1242556 & 2.4939064 & -0.8517784 & 0.3943371 \\
\hline Var PositSL-Intermediate & -0.9680734 & 1.5531469 & -0.6232980 & 0.5330887 \\
\hline
\end{tabular}

From the results of this model, we observe that all the values are negative so this confirms the hypothesis that the factors activity and position have an influence on the variation of antioxidant activity. In Senegal to consume a mango rich in antioxidant activity, you must choose the varieties SL (top position) and Knt (intermediate position). Antioxidants are substances that are present in low concentrations compared to an oxidizable substrate, capable of inhibiting or preventing its oxidation by eliminating free radicals and reducing oxidative stress [11].

\subsection{Study of the Polyphenol Content According to the Variety and the Position}

According to various studies, we have noted that phenolic

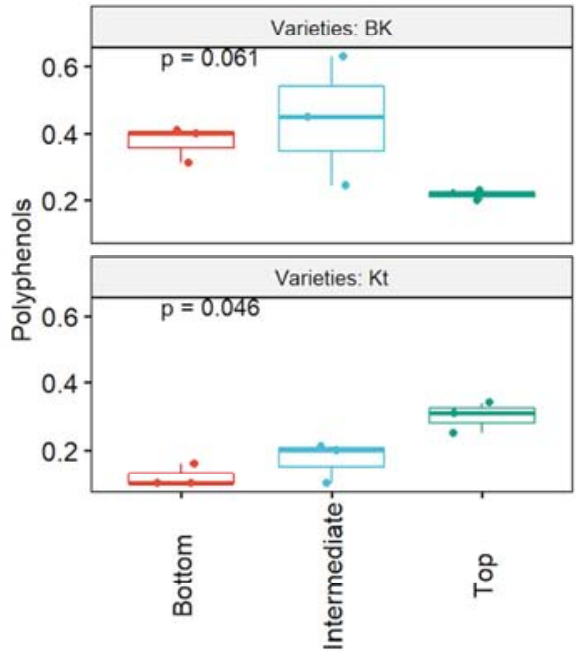

Figure 8. Variation in plyphenol composition by variety.

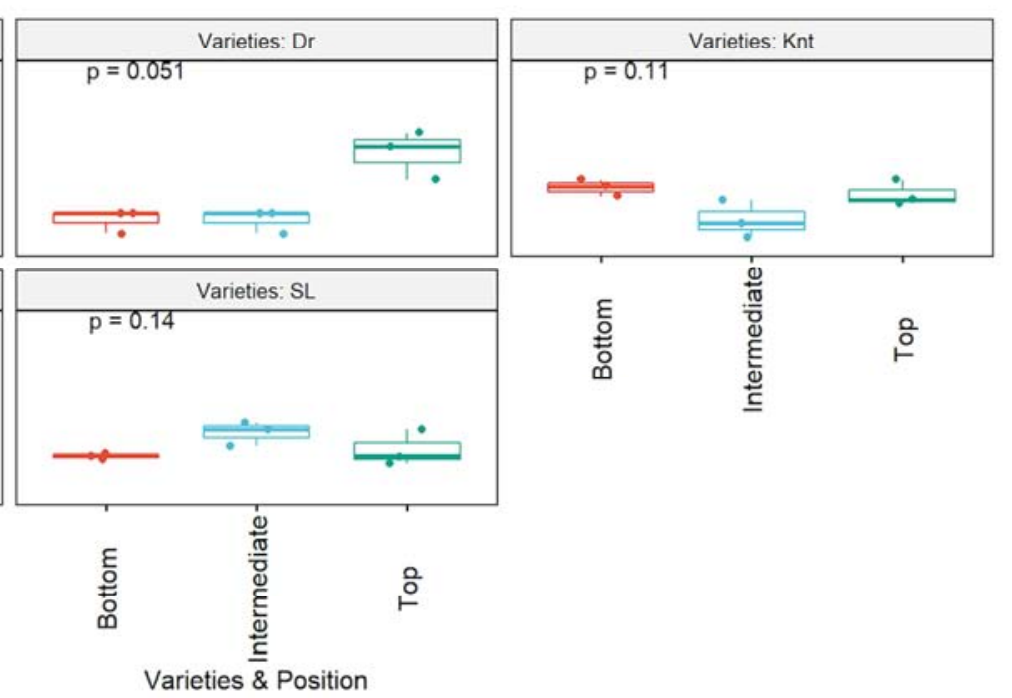

compounds are found throughout the plant kingdom and that they are good antioxidants because they can easily give a hydrogen atom or an electron which would reduce stress oxidizing, forming stable radicals. Polyphenols include phenolic acids (gallic acid), flavonoids (rutin), tannins and coumarins. They are also biologically active molecules which are highly sought after for their antioxidant and anti-radical capacity, among others [12]. Based on the analyzes made on antioxidant activity, we consider that the factors of variety and position have an influence on the polyphenolic composition. To understand this, we have compared the means of the polyphenolic composition within each variety and its positions in the following figure:

Position $\risingdotseq$ Bottom $\risingdotseq$ Intermediate $\risingdotseq$ Top

According to this figure 7, we do not observe a big difference according to the polyphenol composition between the varieties. However, it seems that a difference in this composition exists between positions. To verify this hypothesis, we performed an analysis of variance in the following figure: 


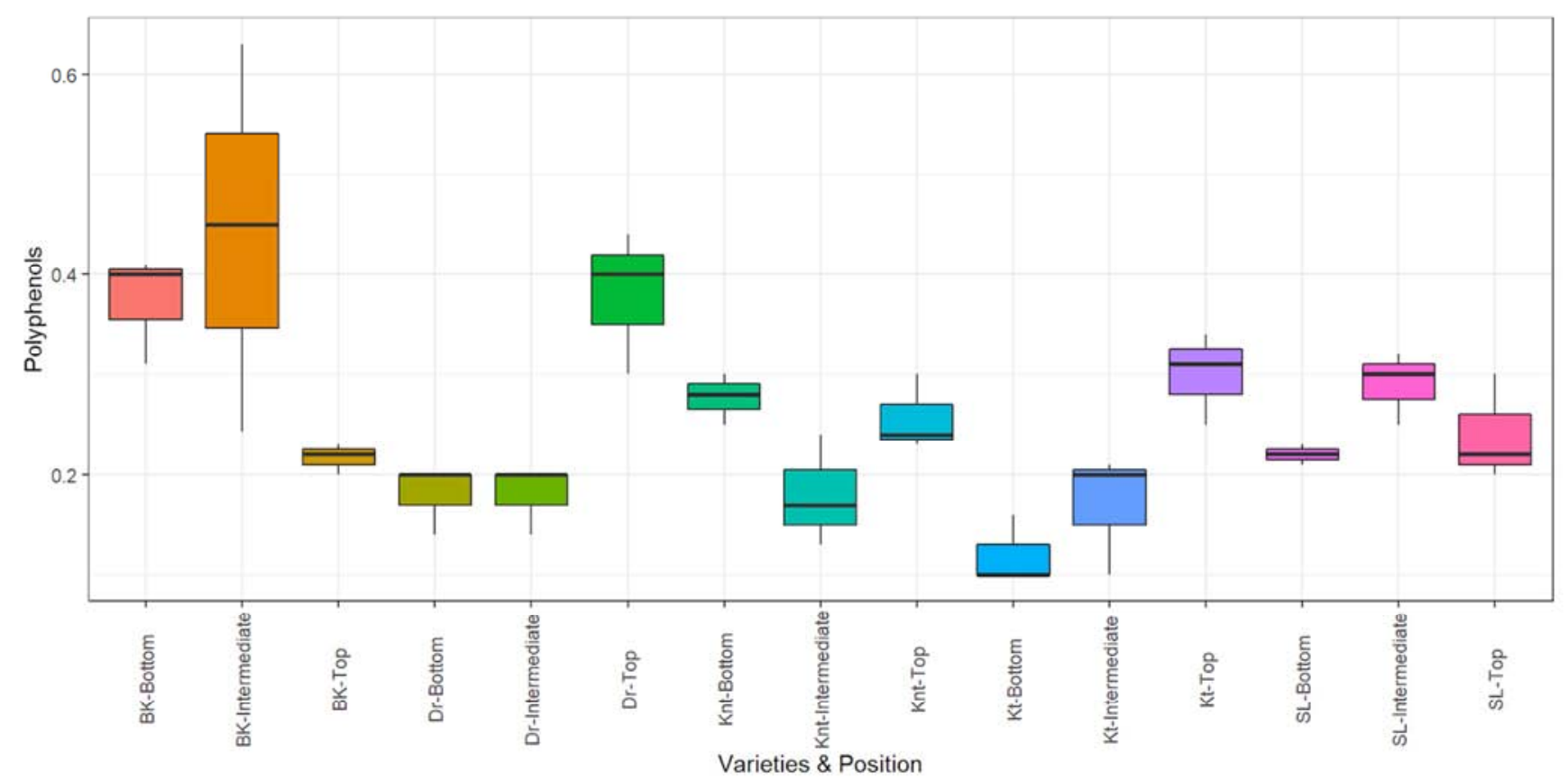

Figure 9. Analysis of variance of the polyphenol content.

Compared to the values on the average, we observe that within the varieties Knt and Dr, a difference in the polyphenolic composition between their top position and the other positions.

From this figure 8, the results show that the polyphenol composition of the intermediate position of the variety $\mathrm{Bk}$ is different from all the others. To find out if this difference is significant, we will set the Intermediate Status of the variety $\mathrm{Bk}$ as a reference in order to model this hypothesis using a GLM (Generalized Linear Model) with a Negative Binomial distribution which is generally best suited for decimal data.

Table 3. Generalized linear model.

\begin{tabular}{|c|c|c|c|c|}
\hline & Estimate & Std. Error & $z$ value & $\operatorname{Pr}(>|z|)$ \\
\hline (Intercept) & -0.8187104 & 0.8694013 & -0.9416945 & 0.3463491 \\
\hline Var_PositBk-Bottom & -0.1665732 & 1.2840235 & -0.1297275 & 0.8967820 \\
\hline Var_PositBk-Top & -0.7106848 & 1.5147015 & -0.4691913 & 0.6389329 \\
\hline Var_PositDr- Bottom & -0.8960880 & 1.6148409 & -0.5549079 & 0.5789576 \\
\hline Var_PositDr- Intermediate & -0.8960880 & 1.6148409 & -0.5549079 & 0.5789576 \\
\hline Var_PositDr- Top & -0.1488736 & 1.2779093 & -0.1164978 & 0.9072580 \\
\hline Var_PositKnt- Bottom & -0.4662315 & 1.4002423 & -0.3329648 & 0.7391608 \\
\hline Var_PositKnt-Intermediate & -0.8960880 & 1.6148409 & -0.5549079 & 0.5789576 \\
\hline Var_PositKnt- Top & -0.5412666 & 1.4333738 & -0.3776172 & 0.7057150 \\
\hline Var_PositKt- Bottom & -1.3015531 & 1.8797971 & -0.6923902 & 0.4886923 \\
\hline Var_PositKt-Intermediate & -0.9532464 & 1.6482244 & -0.5783475 & 0.5630295 \\
\hline Var_PositKt- Top & -0.3852624 & 1.3663712 & -0.2819603 & 0.7779740 \\
\hline Var_PositSL- Bottom & -0.6954173 & 1.5069873 & -0.4614620 & 0.6444672 \\
\hline Var_PositSL-Intermediate & -0.4191640 & 1.3803204 & -0.3036715 & 0.7613782 \\
\hline Var_PositSL- Top & -0.6084060 & 1.4644959 & -0.4154371 & 0.6778219 \\
\hline
\end{tabular}

From the results of this table 3, the model used confirms that the polyphenolic composition of the intermediate position of the variety $\mathrm{Bk}$ is different from those of all the other positions. We can say that the polyphenolic composition varies according to the position but not according to the variety. This difference on the polyphenolic composition is observed at the upper position of the variety Dr. These two varieties have the most important polyphenolic compositions.

\subsection{Study Flavonoid Content According to the Variety and the Position}

Flavonoids are naturally present in fruits and vegetables commonly consumed in the human diet. These bioactive compounds are also found in many drinks: red wine, beer, soy milk, tea and dark chocolate. Two studies in 2007 and 2010 estimated the daily intake at $182 \mathrm{mg}$ in the United Kingdom [13] and $190 \mathrm{mg}$ in the United States [14]. Based on the 
observations made on the contents of total polyphenols and in antioxidant activity, it is considered that the content of flavonoids varies according to the variety and the position.

To understand if the position where the fruit was picked and the variety have an effect on the flavonoid content, we studied the average within each variety and the results are shown in the following figure:

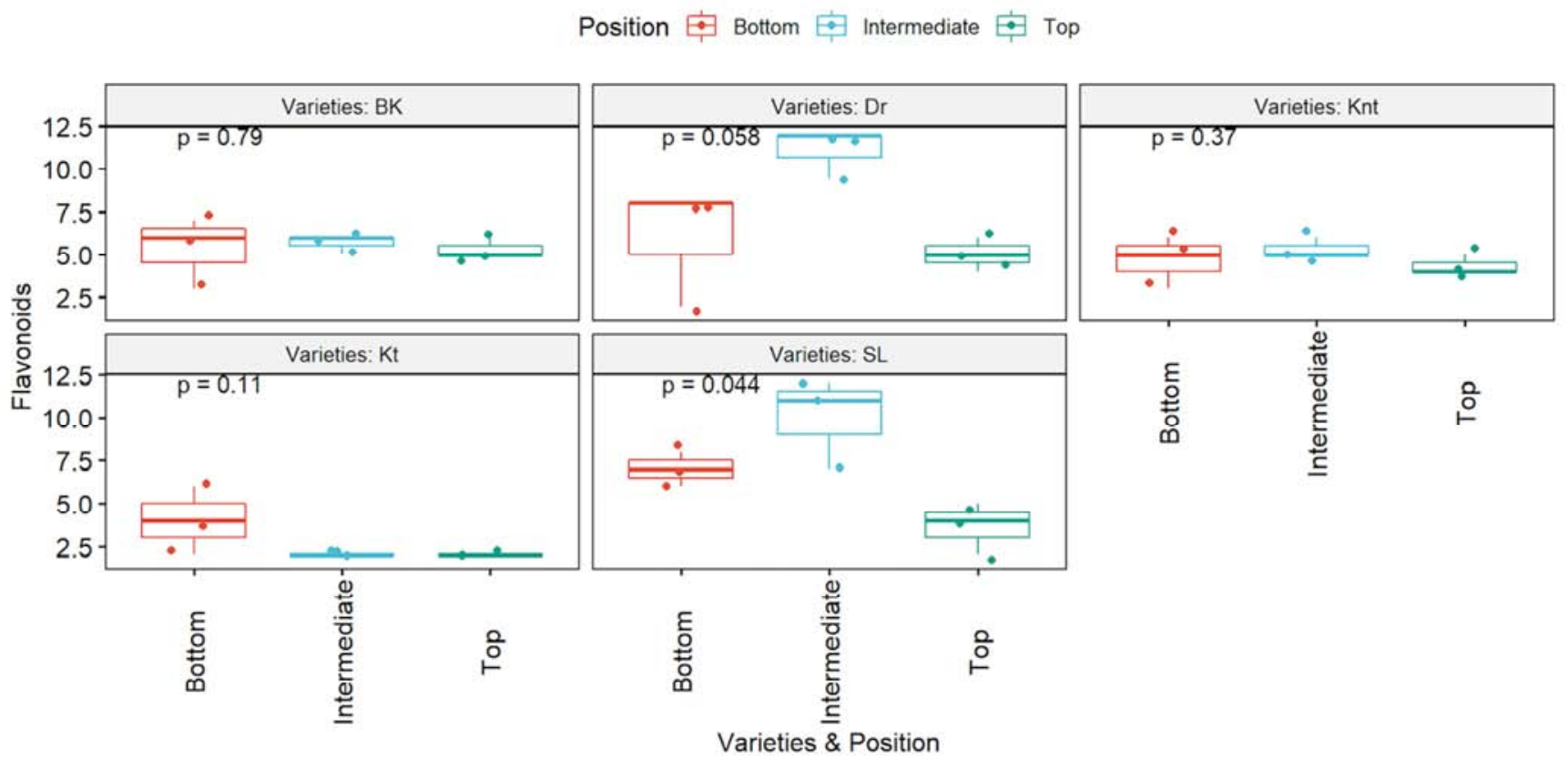

Figure 10. Variation in flavonoid content compared to the variety at the position.

From the results represented in this figure 10, it seems that there is a variation in the content of flavonoids according to the intermediate positions of the variety $\mathrm{Sl}$ and Dr relative to others. To understand if this difference is significant, we performed an analysis of variance from the following figure:

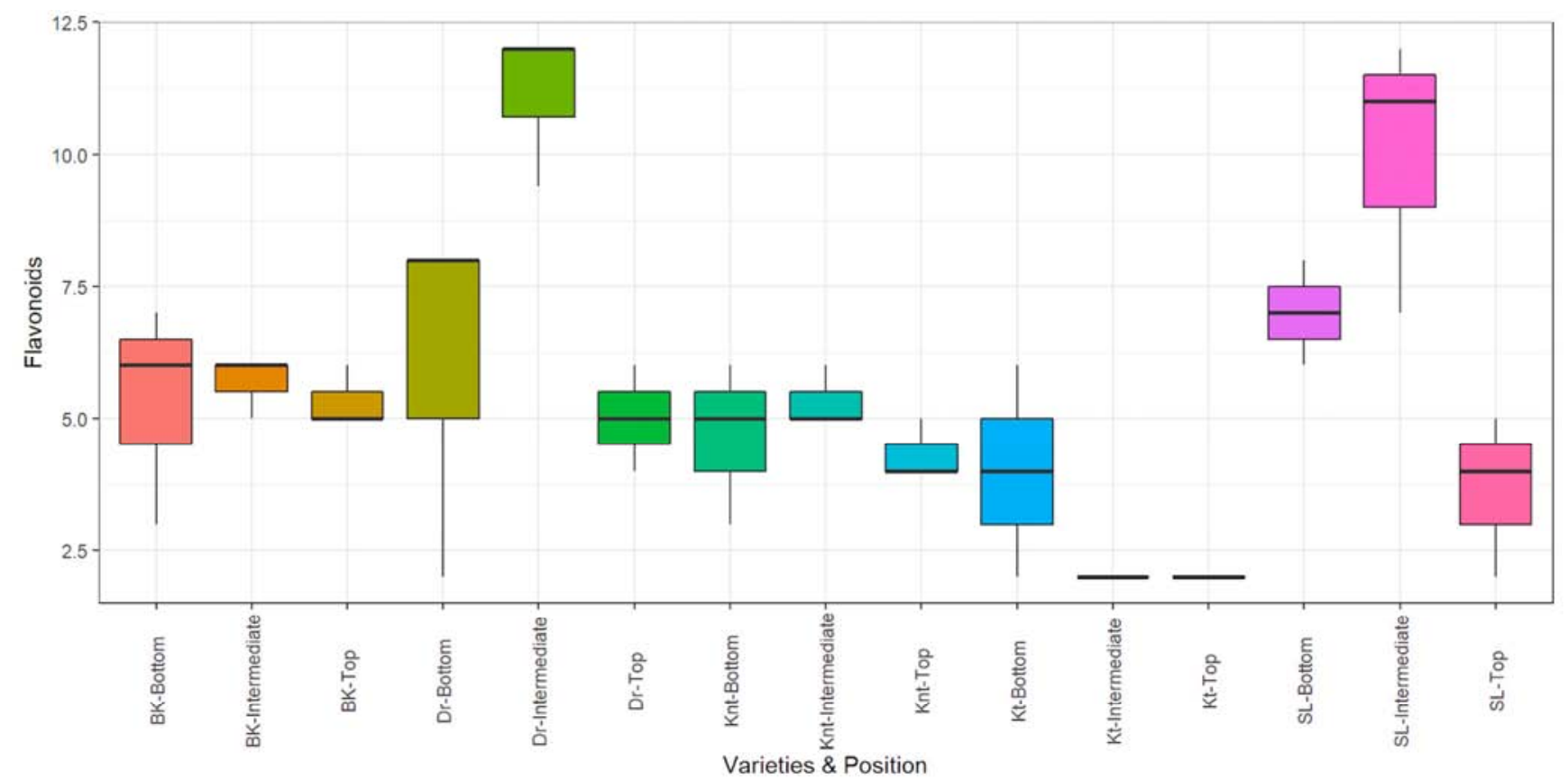

Figure 11. Analysis of variance of the flavonoid content.

From the analysis of this graph, it turns out that the Intermediate position of the varieties Dr and Sl seems to contain the most flavonoids; what remains to be proven via statistical analyzes such as: 
Table 4. Generalized linear model.

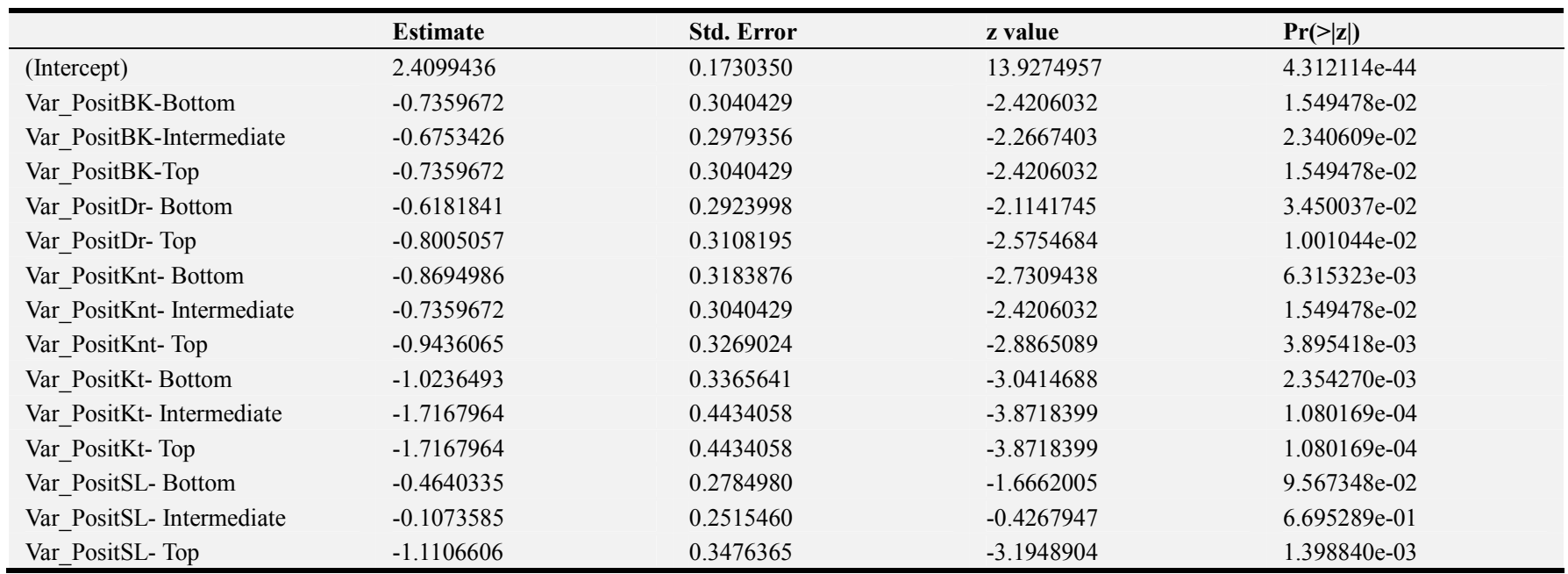

Now we can confirm with certainty that the Intermediate position of the variety Dr contains by far the most flavonoids than the other positions of the other varieties. However, its flavonoid content is not statistically significant compared to the Intermediate position of the variety $\mathrm{Sl}$, which was predictable on graph 8 . Regularly consume foods rich in flavonoids (antioxidants), such as apples and tea, and exercise moderation or even abstinence from alcohol and tobacco. This may be the key to a longer and healthier life, so the Sl variety may be an alternative in Senegal [15].

\section{Conclusion}

Senegal produces many varieties of mango. This great diversity of mangoes exploited makes this country one of the leaders in West Africa with an opening period of six months [16]. While mango is one of the most accessible fruits, studies on biochemical characterization are almost non-existent. According to the results, the local variety $\mathrm{Sl}$ is rich in antioxidants and its consumption can help to fight against cardiovascular diseases on the one hand and to prevent the risks linked to cancer on the other hand. This study on the biochemical composition of antioxidants revealed that the variety and the position where the fruit (mango) was picked have an influence on the contents of total polyphenols, flavonoids and antioxidant activity. From all the observations made, the bottom position has never been the best. So, it would be necessary to try to understand why the composition varies within the same variety depending on the position where the fruit was picked but also if this variation in contents depends on the size of the plant?

\section{References}

[1] Voquaux P., 2002. Fresh ready-to-use fruit known as 4th range. Fruit Processing Technologies, Tec and Doc Editions. 119-156.

[2] Serville Y., 1984. Food value of foods from the 5th and 6th groups. Tremolieres J, ServilleY, Jacquot R, Dupin H, Manual of human nutrition, (2) 291-310.

[3] Gorinstein S, Zemser M, et al. 1999 June Comparative content of total polyphenols and dietary fiber in tropical fruits and persimmon. J Nutr Biochem; 10 (6): 367-71.

[4] https://www.lanutrition.fr/bien-dans-son-assiette/aliments/fruit s/mangue/les-caracteristiques-de-la-mangue

[5] Djioua T., 2010. Improvement of conservation of 4th range mangoes by application of heat treatments and use of conservation in a modified atmosphere. Thesis from the University of Avignon. 169.

[6] Source: report-filièremangue-africa-occ-October 24, 2012-original.

[7] https://www.afterfp7.eu/content/download/4293/32686/versio n/1/file/D1233+SOPs+for+Sensory+Physical+and+textural + a nalisis + for + Group +3 .pdf

[8] Willcox JK, Ash SL, Catignani GL. 2004 Antioxidants and prevention of chronic disease. Crit Rev Food Sci Nutr; 44 (4): 275-95.

[9] Rocha Ribeiro SM, Queiroz JH, et al. 2007 Antioxidant in Mango (Mangifera indica L. Pulp). Plant Foods Hum Nutr.

[10] Singh UP, Singh DP, et al. 2004 Characterization of phenolic compounds in some Indian mango cultivars. Int J Food Sci Nutr 2004 March; 55 (2): 163-9.

[11] Northtrop-Clewes CA, \& Thurnham DI 2007. Monotoring micronutrients in Nutrition, Roland A., Schneider R., Razungles A., Guernevé C., et Cavelier F. 2010. Straightforward synthesis of deuterated precursors to demonstrate the biogenesis of aromatic thiols in wine. Agric. Food Chemistry, (10) 1010-1996.

[12] Mohdaly A. A. A., Smetanska I., Ramadan M. F., Mo-hamed A., Mahmoud S. A. 2011. Antioxidant potential of sesame (Sesamum indicum) cake extract in stabiliza-tion of sunflower and soybean oils. Industrial Crop and Products, (34), 952-959.

[13] Beking K, Vieira A., "An assessment of dietary flavonoid intake in the UK and Ireland. 2010. International journal of food sciences and nutrition, 62 (1), 17-19. 
[14] Chun OK, Chung SJ, Song WO., Estimated dietary flavonoid intake and major food sources of U.S. adults. 2007. The Journal of nutrition, 137 (5), 1244-1252.

[15] https://www.santemagazine.fr/actualites/actualites-alimentatio $\mathrm{n} /$ pomme-the-et

moderation-les-trois-ingredients-pour-une-longue-vie-426367.
[16] https://www.senegal-export.com/exportation-de-la-mangue, 147.html. 